\title{
A Financial Conditions Index for Poland
}




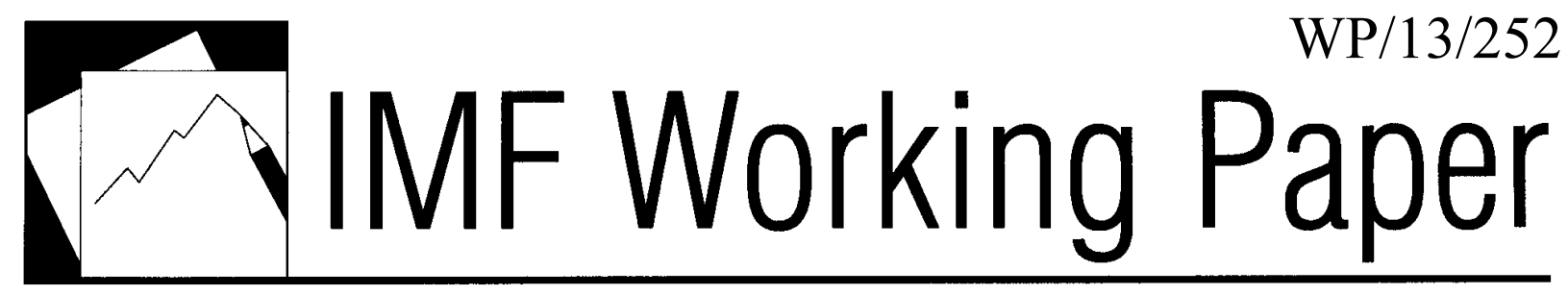

A Financial Conditions Index for Poland

Giang Ho and Yinqiu Lu 


\title{
IMF Working Paper
}

European Department

\section{A Financial Conditions Index for Poland}

\section{Prepared by Giang Ho and Yinqiu Lu ${ }^{1}$}

\author{
Authorized for distribution by Julie Kozack
}

October 2013

\section{This Working Paper should not be reported as representing the views of the IMF. The views expressed in this Working Paper are those of the author(s) and do not necessarily represent those of the IMF or IMF policy. Working Papers describe research in progress by the author(s) and are published to elicit comments and to further debate.}

\begin{abstract}
This paper constructs a financial conditions index for Poland to explore the link between financial conditions and real economic activity. The index in constructed by applying two complementary approaches - factor analysis and vector auto-regression approach. We evaluate the index's forecasting performance against a composite leading indicator developed by the OECD. We found that the FCI is highly correlated with GDP growth, attesting to the importance of financial sector in Poland's economy. In-sample and out-of-sample forecasting exercises indicate that the FCI can outperform the CLI in predicting near-term GDP growth.
\end{abstract}

JEL Classification Numbers: E17, E44, E5

Keywords: Financial conditions index, factor analysis, Poland, vector auto-regression Author’s E-Mail Address:gho@imf.org; ylu@imf.org

\footnotetext{
${ }^{1}$ Strategy Policy and Review Department, and European Department, International Monetary Fund. We are grateful for the very useful comments and suggestions received from Christian Ebeke, Gregorio Impavido, Nir Klein, Julie Kozack, Michal Gradzewicz, and other seminar participants at the National Bank of Poland. The usual disclaimer applies.
} 


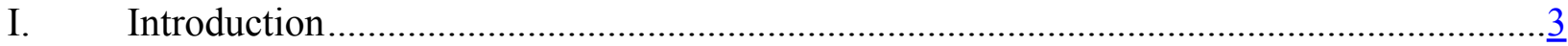

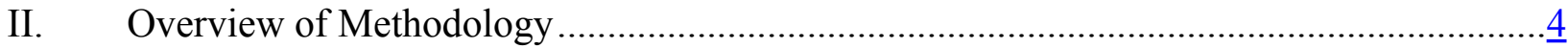

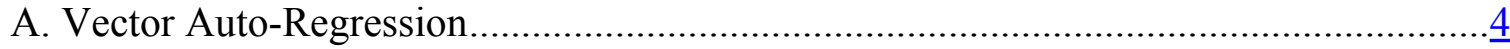

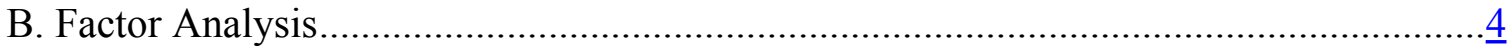

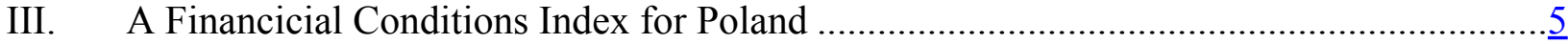

A. Overview of the Constructed FCIs...................................................................... $\frac{5}{6}$

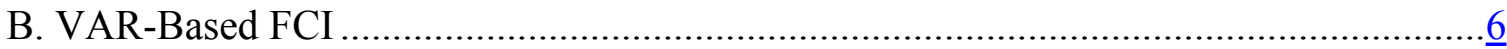

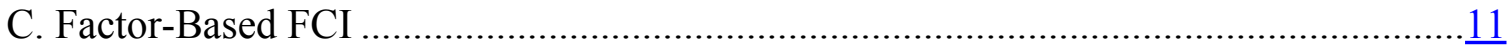

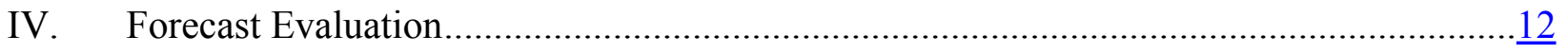

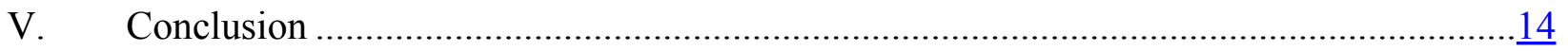

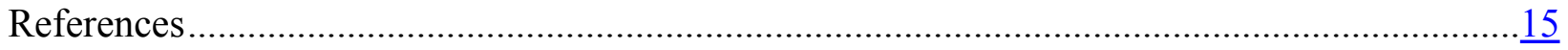

Tables

I. Correlations Between Financial Variables and Real Activity, 2004Q1-2012Q4_.............

II. In-Sample Predictive Tests ............................................................................... $\frac{13}{14}$

III. Out-of-Sample Predictive Tests, Relative RMSE......................................................14

Figure

I. Contributions to FCI, 2004Q1-2013Q1 …................................................................. 


\section{INTRODUCTION}

This paper presents a financial conditions index (FCI) for Poland to explore the link between financial conditions and real economic activity. The FCI combines a wide range of highfrequency financial variables, including external variables, to assess aggregate financial conditions in the economy. The index helps to identify and assess macro-financial linkages and provides a historical perspective in comparing the relative tightness and looseness of financial conditions. It is also useful for the conduct of monetary policy since it captures important channels of monetary transmission, and thus can be used by the monetary authority to gauge the potential impact of monetary policy decisions on the real economy. By including external financial variables in the construction of the FCI, the FCI can capture external spillovers on domestic financial conditions and economic activity. Finally, the FCI may also have forecasting power in pointing to the direction of near-term economic activity, and therefore can be used as an input in macroeconomic forecasting models.

We construct the FCI for Poland based on two complementary methods, i.e., vector autoregression (VAR) and factor analysis (FA). These methods follow recent work on FCIs. ${ }^{2}$ While FA is a purely statistical exercise aiming at extracting the "common factor" from a wide range of financial variables, the VAR method allows us to express the FCI in terms of its contribution to near-term GDP growth. We evaluate the index's forecasting performance against a composite leading indicator (CLI) developed by the OECD. ${ }^{3}$

We find that the constructed FCI for Poland by either method is highly correlated with GDP growth. Among the domestic financial variables, the WIBOR rate, bank lending standards, and the corporate loan spread contribute most to the overall FCI. External variables such as VIX volatility index or EURIBOR-OIS spread are also very important, particularly during the global financial crisis, as they have both a direct and indirect impact on growth (the latter through their influence on domestic financial conditions). In-sample and out-of-sample forecasting exercises indicate that the FCI can outperform the CLI in predicting near-term GDP growth.

The paper is organized as follows. Section II provides an overview of the methodologies for calculating the FCI. Section III presents the index constructed from the VAR and FA, and discusses recent developments. Section IV evaluates the FCI's forecasting properties, and Section V concludes.

\footnotetext{
${ }^{2}$ See e.g. Swiston (2008), Hatzius and others (2010) for the United States, Onsorio and others (2011) for Asia, Hofman (2011) for Russia, and Gumata and others (2012) for South Africa.

${ }^{3}$ The CLI for Poland is constructed from 5 component series: real effective exchange rate, 3-month WIBOR, manufacturing production, unfilled job vacancies, and production of coal. According to the OECD, these are the series that exhibit leading relationship with GDP at turning points of business cycle.
} 


\section{OVERVIEW OF METHOdOLOGY}

\section{A. Vector Auto-Regression}

Using the VAR method, the FCI is calculated as:

$$
F C I_{t}=\sum_{j=1}^{n} \omega_{j}\left(x_{j t}-\overline{x_{j}}\right)
$$

In this formulation, the FCI in each period $t$ is a weighted average of $n$ different financial variables denoted by $x_{j t}$, where $\omega_{j}$ denotes the weight, and $\overline{x_{j}}$ denotes the variable mean over the sample period (2004Q1-2012Q4). ${ }^{4}$ Thus, financial variables enter the FCI as deviations from the mean, which represent shocks to the variables at each point in time.

The financial variables entering the FCI are chosen based on their significant impact on GDP growth, estimated through an exploratory process similar to Swiston (2008). In particular, the weight of each variable $\left(\omega_{j}\right)$ is the cumulative two-quarter impulse response of GDP growth to a one-unit shock to $x_{j t}$. It is estimated from a recursive VAR model consisting of all the financial variables, plus quarterly GDP growth and the GDP deflator. This weight thus measures the relative importance of each financial variable in terms of its impact on growth. The identification of structural shocks is achieved through a Cholesky decomposition (more detail below). The FCI weights will reflect the impact of "pure" structural shocks on growth to the extent that the recursive identification scheme is successful.

The main advantage of a VAR-based FCI over other methodologies is its ability to account for the interdependent relationships among financial variables. For example, the impact of monetary policy tightening includes both the direct effect of higher interest rates on economic activity and indirect effects through the impact of higher interest rates on other financial market variables that in turn affect growth.

\section{B. Factor Analysis}

FA can be used to extract an unobserved common factor that captures the greatest common variation in a group of financial variables. Specifically:

$$
X_{t}-\mu=\beta F_{t}+U_{t}
$$

In this formulation, $X_{t}$ is a vector of financial variables, $\mu$ denotes a vector of variable means, $F_{t}$ is the common factor (unobserved), and $U_{t}$ is a vector of errors assumed to be orthogonal to

\footnotetext{
${ }^{4}$ We do not use time-varying means since our sample is relatively short, which mitigates the concern over possible structural changes in the economy. For example, by 2004 Poland has gone through the disinflation process and established a constant inflation target.
} 
the common factor. Financial variables are chosen for their potential impact on growth (from VAR analysis), but also based on their estimated factor loading, i.e. correlation with the common factor.

The common factor summarizes the information contained in current financial variables. Following Onsorio and others (2011), to obtain the FCI, we purge the common factor of any influence of past economic activity by regressing $F_{t}$ on current and lagged growth:

$$
F_{t}=A(L) y_{t}+\varepsilon_{t}
$$

where $\mathrm{A}(\mathrm{L})$ is the lag operator that captures both current and lagged GDP growth rates, and $y_{t}$ denotes the year-on-year GDP growth rate. The error term, $\varepsilon_{t}$, will be our factor-based FCI, which captures only exogenous developments in financial conditions that predict future economic activity.

\section{A Financial Conditions Index for Poland}

\section{A. Overview of the Constructed FCIs}

The two measures of FCI constructed from VAR and FA are highly correlated with each other, with a correlation of 0.78 . An increasing index indicates easing financial conditions, while a decreasing index implies tightening.

The FCI is highly correlated with GDP growth, attesting to the importance of financial sector in Poland's economy (text chart). For example, the contemporaneous correlation of the VAR-based FCI with annualized quarter-on-quarter growth over the period 2004Q1-2012Q4 is 0.56, and the correlation with two-quarter-ahead growth is 0.67 . The factor-based FCI is uncorrelated with contemporaneous growth by definition, being the residuals of the regression on current and past growth rates. However, it is highly correlated with future growth, e.g.

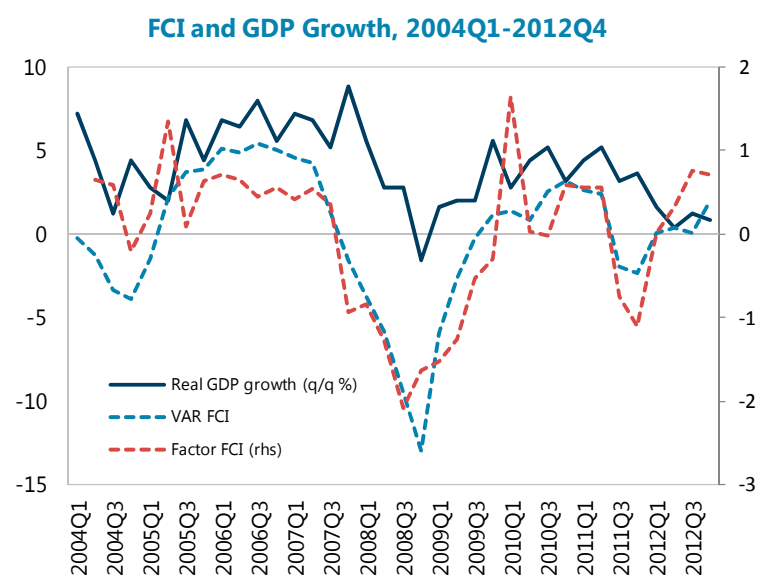
correlation with four-quarter-ahead growth rate is 0.52 , suggesting potential forecasting power.

The VAR-based FCI is measured in terms of contribution to growth, which facilitates intuitive interpretation. For example, between 2007Q4 and 2009Q3, the FCI contributed on average $-5 \frac{1}{4}$ percentage points per quarter to annualized QoQ growth. At the trough of the financial crisis (2008Q4), the economy contracted by 1.6 percentage points (in annualized term), of which adverse financial conditions contributed almost -13 percentage points. In other words, not only the direction of change (easing or tightening) in the FCI matters but also its level. This 
allows us to pinpoint, for example, periods in which financial conditions are tightening (decreasing FCI) but still contributing to growth (positive FCI).

The FCI produced by FA is in a way less intuitive, since it does not take into account the relationship among financial variables or their impact on growth. FA is purely a statistical exercise aimed at extracting as much common variance among the data as possible. The resulting common factor represents an unobserved force driving movements in financial variables, but one that is difficult to attach a meaning to. Nevertheless, an advantage of FA over VAR is that there are fewer constraints in the number of variables that can be included, enabling us to potentially cover a wider spectrum of financial market developments.

\section{B. VAR-Based FCI}

We include both domestic and external financial variables in the FCI. Domestic variables include lending standards from the Senior Loan Officer Opinion Survey (average across corporate loan categories), ${ }^{5} 3$-month WIBOR rate, corporate loan spread, ${ }^{6} 5$-year government bond yield, and the real effective exchange rate (REER). These variables capture various channels through which monetary policy affects the real economy (interest rate, exchange rate, credit, and asset prices). ${ }^{7}$ External variables include the EURIBOR-OIS spread and the VIX index, which represent external financial conditions that would likely affect Polish economy via its banking exposure to Europe and reliance on external financing.

The identification of structural shocks is achieved through a Cholesky decomposition, which assumes that domestic financial conditions do not have contemporaneous effects on growth and inflation, and that domestic developments (real and financial) do not contemporaneously affect external variables. Specifically, we employ the following Cholesky ordering, similar to Swiston (2008): VIX, EURIBOR-OIS, GDP growth, GDP deflator, lending standards, WIBOR, REER, corporate loan spread, government bond yield. The rationale for the ordering among domestic financial variables is the relative sluggishness of the variable; for example, bond yields, corporate lending rates, and REER are relatively fast-moving financial indicators, while the WIBOR rate adjusts to follow the policy interest rates which are set by the Monetary Policy Council, and lending standards are updated every quarter. ${ }^{8}$ GDP is assumed to be more sluggish

\footnotetext{
${ }^{5}$ Lending standards are measured in terms of percent balance (difference between the percentage of surveyed banks easing standards and those tightening standards). The survey is administered quarterly by the National Bank of Poland. The loan categories include long-term loans for large enterprises, short-term loans for large enterprises, long-term loans for small and medium enterprises, and short-term loans for small and medium enterprises.

Standards for household loans are excluded due to their limited impact on growth.

${ }^{6}$ This is the spread between the lending rate for non-financial corporations and the policy interest rate.

${ }^{7}$ We fail to find a significant relationship between GDP growth and equity prices, possibly due to the relatively low level of stock market capitalization in Poland.

${ }^{8}$ The results are quite robust to varying the order among domestic financial variables.
} 
than financial variables, and shocks to financial variables do not affect output at the current stage.

By combining information from various financial indicators, the constructed FCI tracks GDP growth better than any individual indicators (Table 1). The VAR-based FCI also tends to correlate the most with one- and two-quarter ahead growth rates, suggesting potential predicting power for near-term growth. Among the domestic financial variables, lending standards have the highest contemporaneous correlation with GDP growth, while real exchange rate and government bond yield are more related to future growth. External variables (VIX and EURIBOR spread) are also highly correlated to Poland's growth, reflecting Poland's extensive links with Europe and the world not only through the banking system but also in trade.

Table 1. Correlations Between Financial Variables and Real Activity, 2004Q1-2012Q4

\begin{tabular}{lccccc}
\hline & \multicolumn{5}{c}{ Real GDP (annualized QoQ percent change) } \\
\multicolumn{1}{c}{ Variable } & $\mathrm{t}$ & $\mathrm{t}+1$ & $\mathrm{t}+2$ & $\mathrm{t}+3$ & $\mathrm{t}+4$ \\
\hline FCI & $\mathbf{0 . 5 6}$ & $\mathbf{0 . 6 6}$ & $\mathbf{0 . 6 7}$ & $\mathbf{0 . 5 5}$ & $\mathbf{0 . 3 1}$ \\
Lending standards & 0.46 & 0.40 & 0.30 & 0.10 & 0.13 \\
3-mo WIBOR & -0.35 & -0.46 & -0.45 & -0.32 & -0.08 \\
Real exchange rate & 0.03 & -0.06 & -0.10 & -0.31 & -0.26 \\
Corporate loan spread & -0.37 & -0.27 & -0.26 & -0.24 & -0.25 \\
Government 5-yr bond yield & -0.04 & -0.26 & -0.38 & -0.36 & -0.25 \\
EURIBOR spread & -0.36 & -0.46 & -0.57 & -0.64 & -0.51 \\
VIX & -0.37 & -0.42 & -0.50 & -0.43 & -0.40 \\
\hline
\end{tabular}

The text chart below shows the impulse responses of GDP growth to a one-standard-deviation shock in various financial variables, estimated from the VAR model specified above. All responses have the expected sign and most are statistically significant. For example, a 20 basis point increase in the interbank lending rate (WIBOR) is estimated to reduce annualized QoQ growth by roughly 0.3 percentage points in the first quarter, accumulating to over $1 \frac{1}{2}$ percentage points after two years. To the extent that the WIBOR rate closely follows the policy reference rate, this suggests a prominent role of Poland's monetary policy in influencing the real economy. Lending standards also have a significant growth impact: a tightening of average lending standards by one standard deviation (roughly 10 percentage points) is expected to cumulatively reduce growth by $1 \frac{1 / 4}{4}$ percentage points in two years. ${ }^{9}$ An increase in government bond yield and a REER appreciation both hurt growth in the longer run (two to three quarters after shock), but unlike other financial variables their impacts are not immediate.

\footnotetext{
${ }^{9}$ As a benchmark comparison, lending standards (average across all corporate loan categories) tightened by about $86 \mathrm{pp}$ in 2009Q1.
} 


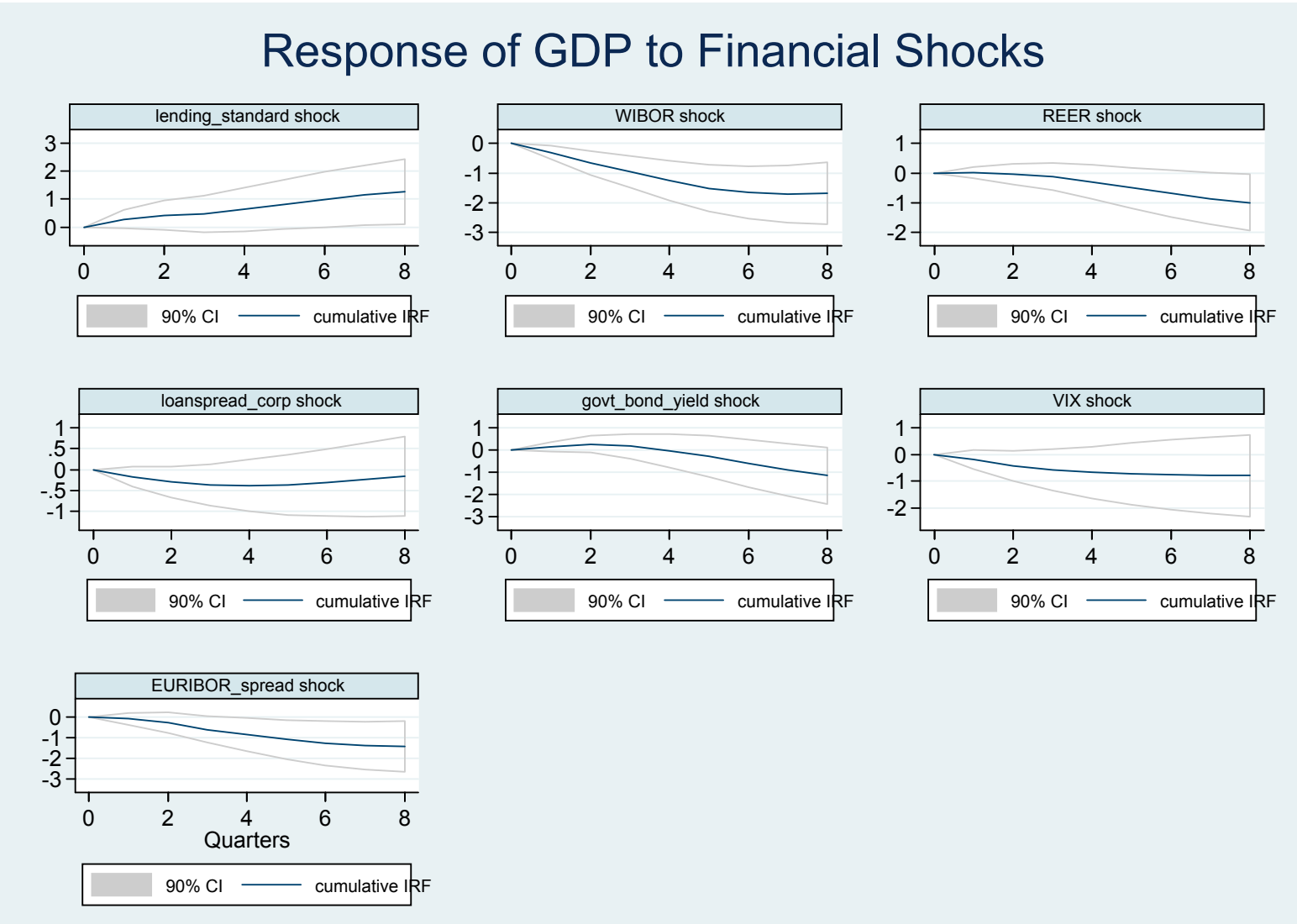

The FCI can be decomposed into relative contributions of various financial variables over the period 2004Q1-2013Q1 (Figure 1). ${ }^{10}$ The contribution of each variable at each point in time is determined by not only its shock at the time but also its estimated impact on growth (or its weight in the FCI). The weights are computed from the impulse responses of growth to various financial shocks presented above. Given the way that the FCI is constructed in this paper, the contribution of each variable is its cumulative contribution to growth after 2 quarters. In other words, if monetary easing takes place at $t$, then the FCI shows the cumulative growth impact of this easing measured at $\mathrm{t}+2$.

\footnotetext{
${ }^{10}$ The decomposition of 2013Q1 is calculated based on the weights calculated over the period of 2004Q1-2012Q4.
} 


\section{Figure 1. Contributions to FCI, 2004Q1-2013Q1 \\ (percentage points of annualized q/q growth)}

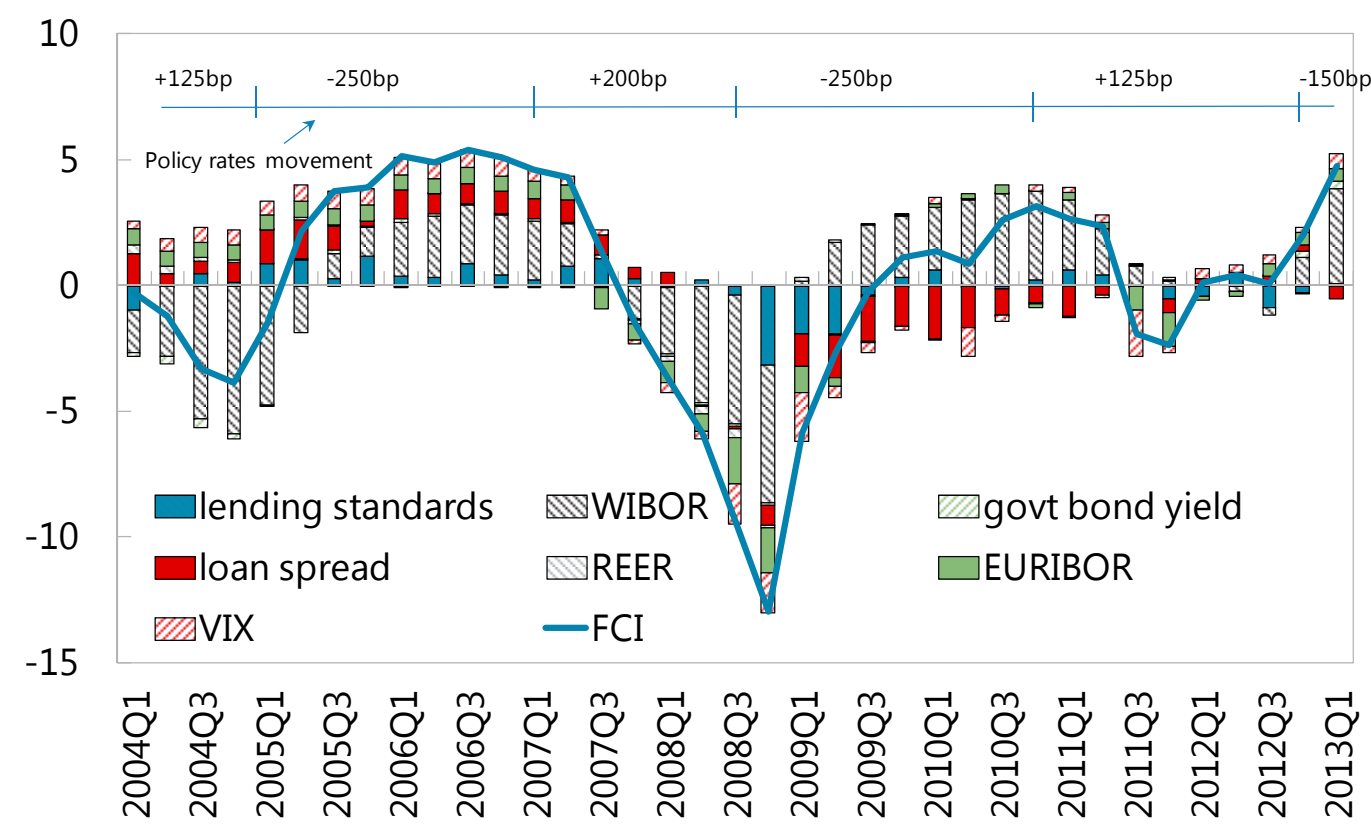

Sources: Haver and IMF staff estimates.

Among the domestic variables, the most significant contributions come from WIBOR, the corporate loan spread, and lending standards. These three variables together contributed on average almost 3 percentage points per quarter in annualized QoQ GDP growth ${ }^{11}$ between 2005Q2 and 2007Q3, when financial conditions were favorable (having positive impact on growth). Indeed, the National Bank of Poland (NBP) entered an easing cycle in 2005Q2 and by 2007Q1 had reduced the policy rate by 250bps, during which time the WIBOR rate closely followed. Lending standards were eased and the spread on corporate loans declined, adding to the favorable conditions. During 2007, a tightening cycle was started by the NBP, and the FCI started to decrease but was still positive, reflecting financial conditions that were tightening but still having positive contribution to growth.

Between 2007Q4 and 2009Q2, the WIBOR rate, corporate loan spread and lending standards together contributed on average $-33 / 4$ percentage points per quarter to growth. During 2008 , the bulk of negative contribution was from WIBOR, which increased by $90 \mathrm{bps}$ between Q1 and Q4 (more than the cumulative hike in policy rates), mainly reflecting a sudden freeze of liquidity in the interbank market. In response to the crisis, the central bank then cut the policy rate by $250 \mathrm{bps}$ between end-2008 and end-2009, alleviating pressure on the WIBOR and contributing to the recovery. Pressures from the interbank market were transmitted to the credit market,

\footnotetext{
${ }^{11}$ This is the cumulative two-quarter impact on growth.
} 
which then impacted GDP growth with a lag. Therefore, it was not until late 2008-early 2009 that tight lending standards and rocketing corporate loan spread started to prove onerous to growth.

External financial conditions also feature prominently in Poland's FCI. In particular, the VAR-based FCI includes the VIX volatility index, which captures general global risk sentiment ("fear index"), and the EURIBOR-OIS spread, which captures liquidity conditions in the euro area's interbank market from which many parent banks of Polish financial institutions get their funding. Both external indicators were acutely affected at the time of the Lehman collapse, and between 2008Q3 and 2009Q1

contributed on average

$-3 \frac{1}{4}$ percentage points per quarter to Poland's GDP growth, almost as much as the total impact of the three leading domestic variables. An examination of the forecast error variance decomposition shows that about 10 percent of the error in Poland growth forecast eight quarters out is due to shocks to VIX and EURIBOR-OIS spread

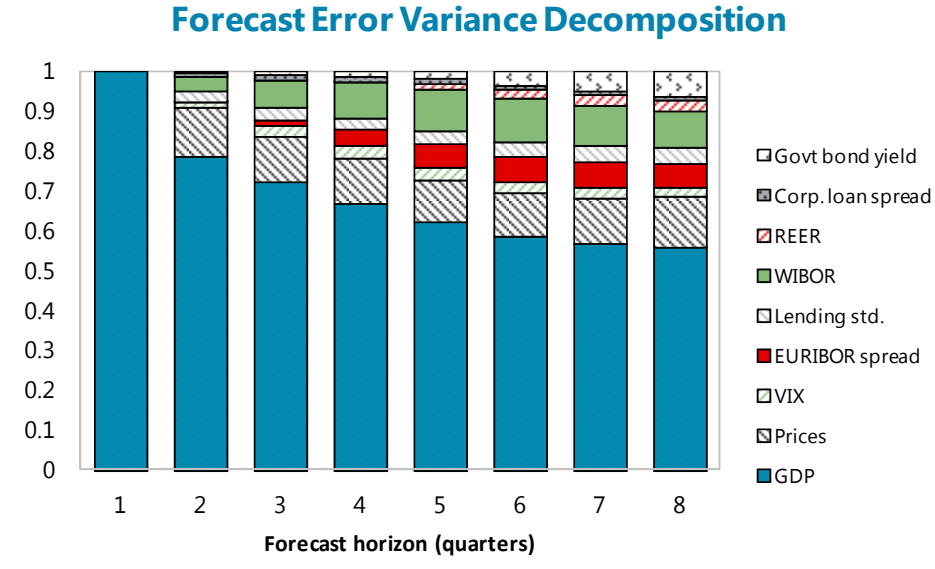
(text chart).

The VIX index and EURIBOR-OIS spread affect growth in Poland partly through their impact on domestic financial conditions. For example, the 3-month WIBOR is very responsive to movements in the EURIBOR-OIS spread, reflecting the large exposure of Poland's financial sector to banks in the euro area. The VIX volatility index does not significantly affect WIBOR, but has large and statistically significant impact on other financial variables (text chart). A worsening of global risk sentiment as indicated by a VIX increase is

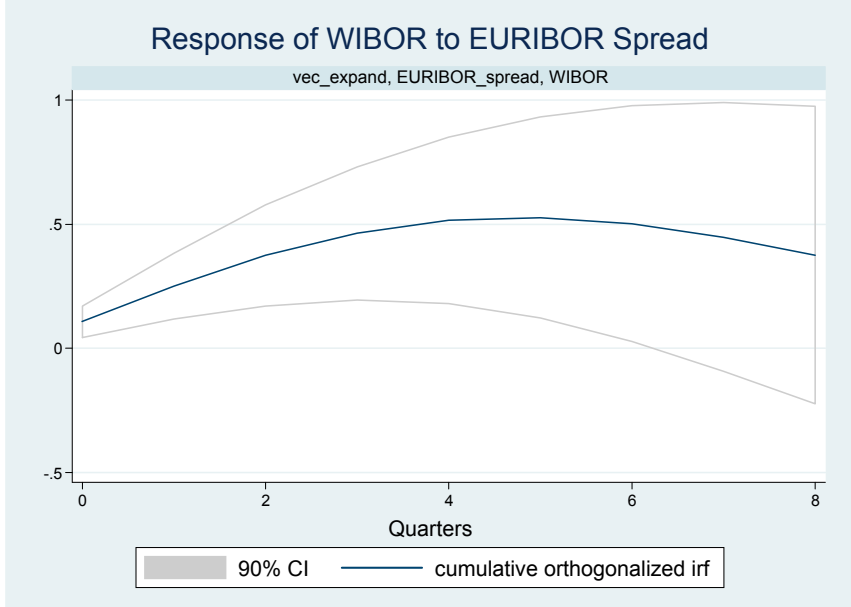
associated with tightened lending standards, higher spread on corporate loans, depreciation of the real exchange rate, and an increase in the government bond yield (text chart). 

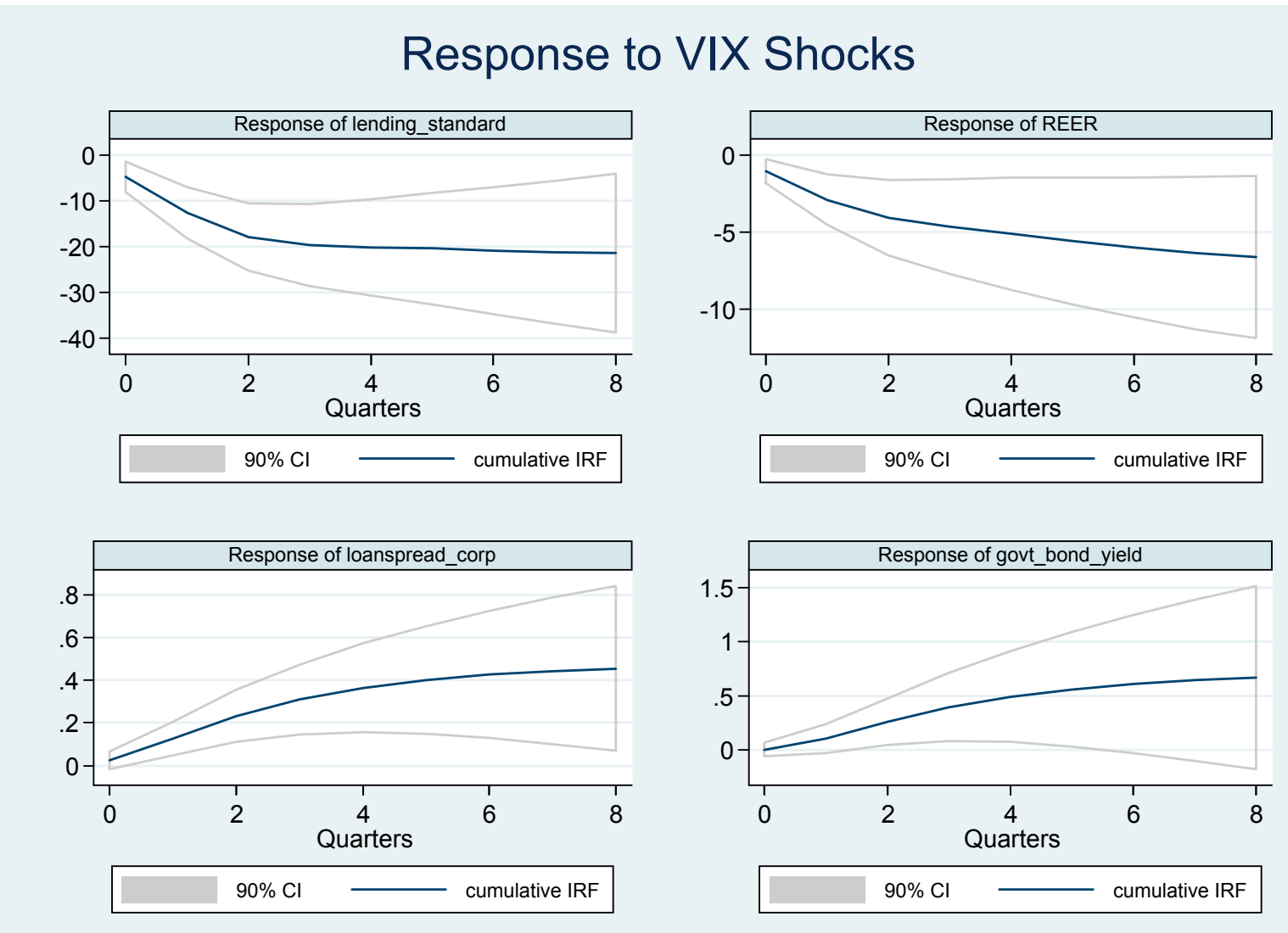

Which aspect of financial conditions is constraining growth at the current juncture can be inferred from the relative contributions of FCI components. Conditions were favorable between early-2010 and mid-2011 mainly on account of low WIBOR rate, but also due to improved external conditions and lending standards that were either neutral or easing. 2011Q3 and Q4 saw a sharply deteriorating FCI due almost entirely to external factors (widening VIX and EURIBOR-OIS spread) related to renewed sovereign and financial stress in peripheral Europe. Latest data show that aggregate financial conditions have started to ease and are again contributing positively to growth. This is due partly to improved external financial conditions, but mainly to easing monetary conditions (the NBP started an easing cycle in November 2012, and the policy rates were cut by a cumulative 150bps by March 2013).

\section{Factor-Based FCI}

Similar to the VAR framework, we include both domestic and external financial variables in the factor-based FCI. These include lending standards, WIBOR, corporate loan rate, REER, and WIG stock index for domestic variables, and VIX, EURIBOR-OIS spread, and S\&P 500 stock 
index for external variables. ${ }^{12}$ They are chosen for their potential impact on growth (from VAR analysis), and as in usual practice, also based on their correlation with the common factor (at least 30 percent). The set of financial indicators included in the factor-based FCI broadly coincides with that used in the VAR method, except for the inclusion of the stock price indices.

The relative "weight" of each variable in the factor-based FCI is captured in the estimated factor loadings (text chart). When there is a single factor extracted, as is the case here, the factor loading is equivalent to the correlation between the variable and the common factor. For example, a factor loading of 0.9 for the WIG stock index implies that the common factor explains 90 percent of the variance in Poland's stock prices. In other words, a substantial part of the factor-based FCI reflects developments in Poland's equity market, irrespective of whether stock prices

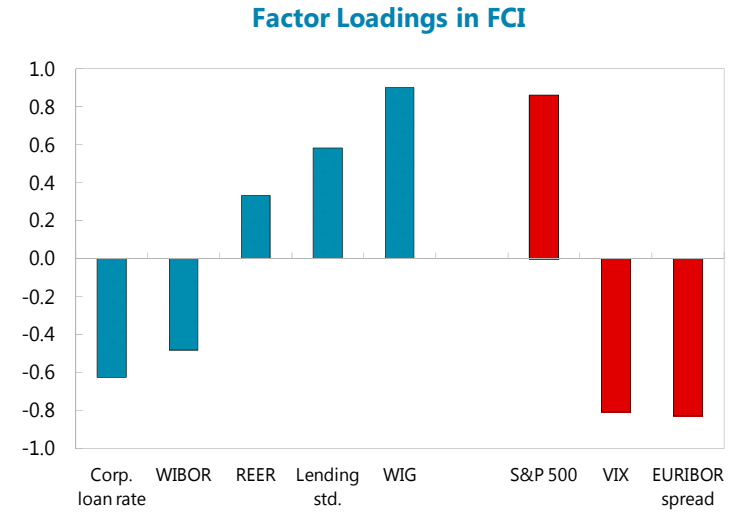
matter for growth.

The factor-based FCI is also driven to a large extent by external factors (S\&P 500 stock index, VIX index, and EURIBOR-OIS spread). All the three external variables have factor loading of more than 80 percent. Higher S\&P 500 index, low VIX and EURIBOR-OIS spread are associated with better financial conditions (higher FCI). On the domestic front, higher WIG index, easy lending standards, and REER appreciation pull up FCI, ${ }^{13}$ while high WIBOR rate and corporate lending rate are associated with a more adverse financial environment.

\section{Forecast Evaluation}

We undertake demonstrative in-sample and out-of-sample forecasting exercises to evaluate the ability of the constructed FCIs in forecasting GDP growth and other macroeconomic variables. As an example, we compare FCI performance to that of the composite leading indicator developed by the OECD. The CLI takes into account not only financial developments but also economic activity variables such as manufacturing production and labor market tightness. Specifically, the following equation is estimated:

$$
y_{t+h}=\alpha+\sum_{i=1}^{3} \beta_{i} y_{t+1-i}+\gamma X_{t}+\varepsilon_{t}
$$

\footnotetext{
${ }^{12}$ REER and the stock price indices enter as year-on-year growth.

${ }^{13}$ Since the FA model does not capture the relationship between financial variables and GDP, an appreciation of REER, mainly driven by an appreciation of domestic currency, corresponds to improving aggregate financial conditions.
} 
where $y_{t+h}$ denotes the $h$-quarter-ahead value of the forecast variable (year-on-year growth in GDP, industrial production, employment, and the unemployment rate), and $X_{t}$ denotes the indicator being evaluated (FCI or CLI). The VAR-based FCI used in this exercise is the fourquarter moving average of the original index, so that it can be compared to year-on-year variables. The number of lags (i.e., 3) on the autoregressive part is chosen based on the Akaike Information Criteria.

The FCIs tend to perform better than CLI in in-sample predictive tests, as indicated by the higher F-statistics and partial R-squared. By adding FCIs, the forecasting power of the autoregressive part has been improved, and the forecasting power of FCIs is stronger than the CLI. The partial R-squared measures the marginal contribution of the index to explaining the forecast variable when lagged parts of growth are kept constant. For example, panel (a) in Table 2 implies that the errors in predicting two-quarter-ahead GDP growth based on its autoregressive parts could be reduced by 48 percent by adding the VAR-based FCI, and 42 percent by adding the factor-based FCI, as opposed to only 22 percent by adding CLI. Similar results hold for predicting industrial production, employment, and unemployment rate. While the VAR-based FCI performs well at the two-quarter forecast horizon, the factor-based FCI tends to dominate at the four-quarter horizon (panel (b) of Table 2). This is consistent with our remark earlier, that the factor-based FCI is constructed such that it captures only the exogenous financial developments that potentially affect future growth.

Table 2. In-Sample Predictive Tests

(a) $h=2$

\begin{tabular}{|c|c|c|c|c|c|c|c|}
\hline \multirow[b]{2}{*}{ Forecast variable } & \multicolumn{4}{|c|}{ F-stat } & \multicolumn{3}{|c|}{ Partial R-squared } \\
\hline & AR & VAR FCI & Factor $\mathrm{FCl}$ & CLI & VAR FCl & Factor $\mathrm{FCl}$ & CLI \\
\hline Real GDP & 7.7 & 17.1 & 14.5 & 9.1 & 0.48 & 0.42 & 0.22 \\
\hline Industrial production & 10.9 & 33.5 & 24.9 & 11.6 & 0.64 & 0.54 & 0.21 \\
\hline Employment & 18.4 & 19.1 & 20.3 & 16.4 & 0.23 & 0.26 & 0.13 \\
\hline Unemployment rate & 36.5 & 50.8 & 42.6 & 40.7 & 0.42 & 0.33 & 0.30 \\
\hline \multicolumn{8}{|c|}{ (b) $h=4$} \\
\hline & \multicolumn{4}{|c|}{ F-stat } & \multicolumn{3}{|c|}{ Partial R-squared } \\
\hline Forecast variable & AR & VAR FCI & Factor $\mathrm{FCl}$ & CLI & VAR FCl & Factor $\mathrm{FCl}$ & CLI \\
\hline Real GDP & 0.7 & 7.0 & 6.0 & 5.2 & 0.49 & 0.45 & 0.41 \\
\hline Industrial production & 0.8 & 7.2 & 7.9 & 7.3 & 0.49 & 0.52 & 0.50 \\
\hline Employment & 4.1 & 10.3 & 23.5 & 6.4 & 0.44 & 0.69 & 0.27 \\
\hline Unemployment rate & 7.5 & 14.8 & 17.6 & 8.5 & 0.45 & 0.51 & 0.21 \\
\hline
\end{tabular}

Note: $\mathrm{h}$ denotes forecast horizon in quarters.

The superior ability of FCI in forecasting near-term growth is also borne out by out-of-sample predictive tests. We examine the root mean squared errors (RMSE), obtained by estimating the model up until 2009Q4 and calculating the forecast errors over the sub-sample 2010Q1-2012Q4 (Table 3). The RMSE is measured relative to that from an autoregressive model, i.e. without either FCI or CLI. Thus, a number less than one indicates better out-of-sample forecasting performance compared to an autoregressive model. Table 3 shows that both the VAR-based and 
factor-based FCI performs better than the composite leading indicator and the autoregressive model in predicting two- and four-quarter-ahead GDP growth, while the autoregressive model remains superior for forecasting employment growth and the unemployment rate.

Table 3. Out-of-Sample Predictive Tests, Relative RMSE

\begin{tabular}{l|ccc|ccc}
\hline & \multicolumn{3}{|c|}{$\mathrm{h}=2$} & \multicolumn{3}{c}{$\mathrm{h}=4$} \\
\multicolumn{1}{c|}{ Forecast variable } & VAR FCl & Factor FCl & $\mathrm{CLI}$ & VAR FCl & Factor FCl & $\mathrm{CLI}$ \\
\hline Real GDP & $\mathbf{0 . 8 8}$ & $\mathbf{0 . 8 8}$ & 0.98 & 0.81 & $\mathbf{0 . 7 2}$ & 1.09 \\
Industrial production & $\mathbf{0 . 9 4}$ & 1.42 & 0.97 & 1.23 & 1.10 & 1.03 \\
Employment & 1.12 & 1.02 & 1.13 & 1.21 & $\mathbf{0 . 5 8}$ & 1.41 \\
Unemployment rate & 1.66 & 1.18 & 1.57 & 2.04 & 1.10 & 2.56 \\
\hline
\end{tabular}

Note: RMSE relative to AR model, $h$ denotes forecast horizon in quarters.

\section{Conclusion}

In this paper we construct a financial conditions index for Poland using two alternative models, namely VAR and FA. Decomposition of the VAR-based FCI into relative contributions of the individual financial indicators helps further our understanding of macro-financial linkages in Poland's economy. In particular, the WIBOR rate, lending standards, and the corporate loan spread play major roles in driving aggregate financial conditions due to their strong co-movement with the business cycle. External indicators capturing the degree of financial stress globally and in the euro area also prove important. The FCI can be usefully employed as an analytical tool to inform monetary policy analysis as well as near-term growth forecasting. A caveat to keep in mind is that the FCI is conditioned on the static historical relationship between real and financial variables; therefore, if this relationship has changed, the model would need to be reassessed. 


\section{References}

Gumata, Nombulelo, Nir Klein, Eliphas Ndou, 2008, “A Financial Conditions Index for South Africa,” IMF Working Paper 08/161 (Washington: International Monetary Fund).

Hatzius, Jan, Peter Hooper, Frederic Mishkin, Kermit L. Schoenholtz, and Mark W. Watson, 2010, "Financial Conditions Indexes: A Fresh Look after the Financial Crisis," NBER Working Paper No.16150.

Hofman, David, 2011, “A Financial Conditions Index for Russia,” IMF Country Report 11/295 (Washington: International Monetary Fund).

Osorio, Carolina, Runchana Pongsaparn, D. Filiz Unsal, 2011, “A Quantitative Assessment of Financial Conditions in Asia," IMF Working Paper 11/170 (Washington: International Monetary Fund).

Swiston, Andrew, 2008, “A U.S. Financial Conditions Index: Putting Credit Where Credit is Due,” IMF Working Paper 08/161 (Washington: International Monetary Fund). 